\title{
Malignant Narcissism in Tsugumi Ohba's Death Note: Should we Empathize with the Criminally Un-Empathic?
}

\author{
Anshuman A. Srivastava ${ }^{1} \cdot$ Douglas J. Opler $^{1}$ \\ Received: 30 December 2019 / Accepted: 23 April 2020 / Published online: 12 May 2020 \\ (C) Academic Psychiatry 2020
}

Authors have examined psychological themes in American superhero mythos [1-4]. Japanese comics, or manga, are popular in Japan and growing in popularity in the United States, surpassing American comics in sales in the United States in 2018 [5]. As such, they too deserve examination for psychological relevance. Here, we delve into the topics of empathy, countertransference, and diagnosis as raised by one such manga. Empathy is the ability to vicariously understand another's emotions, perspectives, experiences, and motivations [6]. Empathy is required of physicians and particularly psychiatrists [7]. Our responsibility to empathize with the criminally un-empathic is raised by a portrayal of personality disorder in the manga series Death Note. The series, by Tsugumi Ohba, chronicles the actions of the character Light Yagami as he tries to create a crime-free utopia. Yagami, facilitated by a lack of empathy and a narcissistic belief in his own righteousness, performs cruel criminal acts-yet the story portrays the antihero sensitively, never entirely condemning him. We discuss his differential diagnosis, including the syndrome of malignant narcissism described by psychoanalyst Otto Kernberg $[8,9]$. We discuss the clinical utility of countertransference and empathy when dealing with criminally un-empathic patients. With the disclaimer that understanding does not imply approval, we argue that the sensitive, empathic portrayal of a criminally un-empathic character by the series provides a model for psychiatrists when faced with similarly unempathic patients.

As an educational exercise, volume one of Death Note can be comfortably read within 1-2 days. Medical students and first-year residents can practice diagnostic skills on Light Yagami with reference to the DSM 5. In addition to honing the fundamental skill of DSM-based diagnosis, trainees also

Anshuman A. Srivastava

anshu411@gmail.com

1 Rutgers New Jersey Medical School, Newark, NJ, USA learn to look beyond the DSM when conceptualizing cases through introduction to the diagnosis of malignant narcissism. Trainees' emotional and intellectual reactions to Yagami should be elicited as an exercise towards recognizing countertransference. Whether Yagami deserves empathy versus the separate question of whether there is utility to empathy towards un-empathic patients should be asked, followed by a tutorial regarding the clinical utility of empathy, as introduced in this article and its references, particularly Ross and Watling [7]. Advanced residents, who have worked with a wider array of patients, should also read Maltsberger and Buie [10] and discuss their negative countertransferential responses to real cases to move the discussion from abstract fictional cases to more emotionally fraught, real-world examples. Other characters that are portrayed sensitively in media may similarly be examined, such as Avengers: Endgame's Thanos, who killed half the universe's population but genuinely believes his own righteous rationale.

As Death Note begins, Light Yagami is a high school senior who aspires to become a police detective like his father [11]. He is nationally recognized for his academic achievement, and his family, teachers, and friends idolize him for his intellect. One day while he is at school, he notices a notebook lying in the courtyard. He picks it up and sees "Death Note" written on the front. After opening it, he finds instructions that tell him that writing a person's name in the book will result in their death. At first, Yagami does not believe this and decides to not write anything in the book, but his curiosity eventually overcomes him. He sees on the news that an armed man has taken hostages at a local elementary school, so he writes the name of this man in the "Death Note." Moments later, children and teachers run out of the elementary school, and news reporters confirm that the armed man has died. Following this, he struggles to cope with having killed a person, and he questions whether his actions were justified or not. He eventually decides that what he did was right and that he is the only person courageous and intelligent enough to rid the world of crime, so he begins to 
use the "Death Note" to kill criminals. When police and FBI agents try to find him, he uses the "Death Note" to kill them as well. He comes to believe that anyone who stands in his way of making a crime-free world is evil and deserves to be punished just like criminals. In the first volume, he even says that he will "make a world inhabited by people [he] decide[s] are good," demonstrating a grandiose belief in his ability to recognize good and evil better than anyone else [11]. As the series goes on, he continues to kill criminals, but he also kills many innocent people who try to stop him. After 6 years, he is finally caught by the police [11].

Despite trying to decrease crime, Yagami exhibits many antisocial and narcissistic traits. He states that boredom was a major driving force behind him deciding to use the "Death Note." He expresses multiple times that he would, without hesitation, kill his family to protect himself, and he manipulates and deceives others to avoid being caught by law enforcement. Risk taking to counter boredom, manipulativeness, and lack of empathy are traits of antisocial and narcissistic personality disorder [12]. Diagnostic criteria for antisocial personality disorder include a disregard for and violation of others' rights, being $\geq 18$ years old, conduct disorder before age 15 , and antisocial traits outside of psychotic or manic episodes [12]. Disregard and violation of others' rights is subcategorized into seven traits, of which three need to be present. These are failure to conform to social norms or laws, deceitfulness, impulsivity, irritability/aggressiveness, disregard for wellbeing of self and others, irresponsibility, and remorselessness [12]. Yagami exhibits disregard for the law, deceitfulness, aggressiveness, and disregard for the safety of others, so he fulfills this criterion. He is $\geq 18$ for most of the series. Little is shown of Yagami's childhood, but it can be inferred from parents' and teachers' comments that he was a well-behaved child and did not exhibit overt conduct disorder. No mania or psychosis is seen. Ultimately, he fulfills three of four diagnostic criteria for antisocial personality disorder.

Yagami's narcissism is prominent. Narcissistic personality disorder entails grandiosity, preoccupation with power and success, a belief that the narcissist is special and should associate only with those of a similar standing, desire for admiration, feelings of entitlement, exploitative behavior, lack of empathy, a belief that others envy them, and arrogance [12]. Five of these need to be identified in multiple contexts to meet criteria [12]. Yagami proclaims himself a "god" to be worshiped, scoffs at those less intelligent, and manipulates for his own benefit without remorse. He has a craving to be the smartest person in every situation and enjoys when others envy him. He also believes that he is morally superior to those around him. Yagami displays all nine diagnostic traits of narcissistic personality disorder.

Although not in the DSM 5, the syndrome of malignant narcissism incorporating narcissistic, antisocial, and paranoid tendencies with egosyntonic aggression was described by psychoanalyst Otto Kernberg [8, 9]. Yagami's aggression is clearly egosyntonic, and he develops paranoid tendencies out of fear that others will find him out. With a mix of narcissistic, antisocial, and paranoid traits, Yagami fulfills Kernberg's criteria and can be considered a malignant narcissist.

Light Yagami is an iconic character in manga. Over a decade after the manga's release, fans continue to debate whether he is "good" or "bad" [13]. Some believe he is a hero willing to do whatever it takes to make the world a better place while others believe he is a villain [13]. At the beginning of Death Note, Yagami wants to make the world better by becoming a detective, and before finding the "Death Note," he even volunteered with the police department to help detectives solve cases. It is unclear whether Yagami did this to receive accolades, which would be consistent with malignant narcissism, or whether his intentions were noble. Nevertheless, by including these positive actions and having other characters argue for the societal benefit of Yagami's actions, Ohba depicts Yagami with nuance that forces the reader to see things from Yagami's point-of-view. While any compunction is short-lived, after Yagami begins writing names in the "Death Note," he transiently has nightmares and loses weight, pulling for empathy from the reader [11]. Yagami is a young man with a loving support system, strong intellect, and the ability to take initiative, yet despite all of this his malignant narcissism distorts his perception of right and wrong, allowing him to believe that he has the right to kill and exploit anyone to create his crime-free world. The ambivalent depiction of Yagami facilitates empathy in the reader, as evinced by the polarization of fans who cannot agree on whether he is a hero or a villain. The series presents his criminal behaviors in such a way as to encourage readers to consider his perspectives, motivations, and emotions - even in the face of his unethical, maleficent actions.

Empathy has multiple roles in psychiatry. It allows development of therapeutic alliance and is an instrumental part of the psychiatrist-patient relationship which positively influences outcomes [6,7]. Empathy is important in allowing a psychiatrist to understand and influence a patient [7], and it has been categorized in different schemas, including emotional/affective empathy versus cognitive empathy. Emotional/affective empathy entails the empathizing individual experiencing the other's affective experience. For example, when interacting with a sad child, the emotionally empathizing individual also feels sad. In contrast, cognitive empathy entails an intellectual ability to understand another's perspectives and emotions without necessarily recapitulating the affect in the empathic actor [14]. In autism, cognitive empathy is deficient while emotional empathy remains intact. In antisocial personalities and narcissism, emotional empathy is deficient, but cognitive empathy and theory of mind remain intact [15]. 
An alternative schema looks at the functional use of empathy by psychiatrists. Ross and Watling discuss three different functional types of empathy: relational empathy, transactional empathy, and instrumental empathy [7]. Mutualistic relational empathy naturally emerges when psychiatrist and patient are comfortably and therapeutically aligned towards a common goal. Transactional empathy, however, requires collaborative discussions between patient and psychiatrist to negotiate differences in perspective and achieve a common understanding, thereby helping the patient engage in treatment. Instrumental empathy involves application of advanced knowledge by the psychiatrist to develop understanding of the patient's inability to cooperate with treatment. All three types require both emotional and cognitive understanding of the patient's perspective, but the transition from relational to transactional to instrumental empathy requires increasing degrees of conscious and intentional application of empathy by the psychiatrist. Transactional empathy allows the psychiatrist and the patient to negotiate to an understanding of the role each will have in treatment, thereby facilitating engagement by the patient. Instrumental empathy allows the psychiatrist to manage their reaction to the patient and guide an unwilling patient through treatment, as in the case of involuntary psychiatric commitment, for example. Of relevance in avoiding moral quandary, it should be noted that any understanding engendered by empathy does not equate with approval of a patient's outlooks or behaviors.

To employ empathy, psychiatrists must recognize negative countertransference. Maltsberger and Buie described countertransferential hatred as a common response to suicidal, psychotic, borderline, and narcissistic patients [10]. These patients evoke aversion and malice in the psychiatrist. A craving for any relationship by such needy patients induces them to sadomasochistically provoke malicious attention from psychiatrists, to deleterious effect, including patient suicide. Hatred towards patients is uncomfortable, so we defend against hatred with immature defenses, including repression, projection, reaction formation, self-hatred, and distortion, leading to rejection of the patient and empathic failure. Immature defenses reduce negative affect by obscuring it from consciousness [16], allowing the psychiatrist to reduce distress by failing to recognize hatred. Active survey of countertransference is the necessary safeguard. Clues to unrecognized negative countertransference include fear, foreboding, guilt, boredom, impatience, an inclination to avoid or escape, anticipated relief around imminent discharge or termination, belief by the psychiatrist that a patient hates them, failure to set limits around patients' acting out, going above-and-beyond normal care, and/or active malice or disgust towards a patient. Counterintuitively, acceptance by the psychiatrist of negative countertransference, in lieu of defense, can free them from the impulse to act adversely and allow for empathy. Supervision and/or peer input around countertransference is imperative when acceptance is difficult [10].
In cases of unrepentant real-world versions of Light Yagami, namely criminal antisocials, narcissists, and malignant narcissists, there are practical reasons why psychiatrists should continue to be empathic. Firstly, failures of empathy provide diagnostic information which might be lost if not recognized [17]. Some disorders of empathy, such as autism, have features amenable to intervention. Given the utility of empathy in therapeutic alliance, maintaining empathy in the case of treatable disorders would facilitate this. Although data on successful treatment of malignant narcissism is lacking, therapeutic communities, pharmacotherapy, DBT, and couples, family, or individual therapy might be productive; therefore, empathy might still be important for optimizing treatment [18]. However, psychiatrists often work with criminally un-empathic patients when psychiatric treatment is not the goal. Consultation-liaison psychiatrists, forensic psychiatrists, and family therapists, among other examples, may have working goals with antisocial or narcissistic patients besides cure and symptom relief, such as eliciting compliance with medical care during hospitalization, reducing antisocial behaviors in forensic environments, or resolving familial conflict. Maltsberger and Buie point to the danger of unrecognized negative countertransference in these situations, which can interfere with deliberate application of empathy. Ross and Watling point to the utilitarian importance of continued empathy on the part of the psychiatrist involved in such roles: use of transactional and instrumental empathy allows the psychiatrist to assist an unwilling patient with engaging in care and with guidance through a process in which they remain unwilling. With the understanding that empathy does not require approval of a patient's behavior, our goal, as psychiatrists, should be without exception to stay alert to our negative countertransference and its potential adverse effects, remain empathic to patients, and not recapitulate the insensitivity which such patients might level at us.

Acknowledgements None.

Funding Sources No funding provided.

\section{Compliance with Ethical Standards}

Disclosure Conflict of Interest On behalf of all authors, the corresponding author states that there is no conflict of interest.

\section{References}

1. Caruth E. Hercules and superman: the modern day mythology of the comic book, some clinical applications. Journal of the American Academy of Child Psychiatry. 1968;7(1):1-12.

2. Wheeler Vega JA. Generativity and its vicissitudes in Logan and the X-men series. Psychoanal Rev. 2019;106(5):455-74.

3. Widzer ME. The comic-book superhero. A study of the family romance fantasy. Psychoanal Study Child. 1977;32:565-603. 
4. Packer S. Superheroes and superegos: analyzing the minds behind the masks. ABC-Clio: Santa Barbara; 2009.

5. Why Are Manga Outselling Superhero Comics? Rutgers Prof Knows. Tap into New Brunswick. 2019. http://www.tapinto.net/ towns/new-brunswick/sections/arts-and-entertainment/articles/ why-are-manga-outselling-superhero-comics-rutgers-prof-knows. Accessed 18 Dec 2019.

6. Elliott R, Bohart AC, Watson JC, Murphy D. Therapist empathy and client outcome: an updated meta-analysis. Psychotherapy (Chic). 2018;55(4):399-410.

7. Ross J, Watling C. Use of empathy in psychiatric practice: constructivist grounded theory study. BJ Psych Open. 2017;3:26-33.

8. Kernberg OF. An ego psychology and object relations approach to narcissistic personality. American Psychiatric Association Press, Psychiatry, Annual Review. 1982:510-23.

9. Kernberg OF. Malignant narcissism continuing medical education tapes. Tape 1 through 3. California: CME, Inc.; 1990.

10. Maltsberger JT, Buie DH. Countertransference hate in the treatment of suicidal patients. Arch Gen Psychiatry. 1974;30(5):625-33.

11. Ohba T. Death note, vol 1-13. San Francisco, CA: VIZ Media, LLC; 2003.
12. American Psychiatric Association. Diagnostic and statistical manual of mental disorders. fifth ed. Arlington, VA: American Psychiatric Association; 2013.

13. Chapman J. Ten years of death note: is light the bad guy? Anime news network. 2016. https://www.animenewsnetwork.com/feature/ 2016-03-18/ten-years-of-death-note-is-light-the-bad-guy/.99957. .

14. Lockwood P. The anatomy of empathy: vicarious experience and disorders of social cognition. Behav Brain Res. 2016;311:255-66.

15. Blair RJ. Responding to the emotions of others: dissociating forms of empathy through the study of typical and psychiatric populations. Conscious Cogn. 2005;14(4):698-718.

16. Vaillant G. Adaptive mental mechanisms: their role in a positive psychology. Am Psychol. 2000;55(1):89-98.

17. Kirmayer LJ, Lemelson R, Cummings C, editors. Empathy and Alterity in Psychiatry. In: Re-visioning psychiatry: cultural phenomenology, critical neuroscience and global mental health. New York: Cambridge University Press; 2015. p. 141-67.

18. Goldner-Vukov M, Moore LJ. Malignant narcissism: from fairy tales to harsh reality. Psychiatr Danub. 2010;22(3):392-405.

Publisher's Note Springer Nature remains neutral with regard to jurisdictional claims in published maps and institutional affiliations. 